\title{
Stigmatization and discrimination as predictors of self-esteem of people living with HIV and AIDS in Nigeria
}

\author{
Dorothy Ebere Adimora ${ }^{1}$, Eucharia Nchedo Aye ${ }^{2}$, Immaculata Nwakaego Akaneme ${ }^{1}$, \\ Edith Nwakaego Nwokenna ${ }^{3}$, Francis Ekenechukwu Akubuilo ${ }^{3}$
}

1. Department of Educational Foundations, Educational Psychology, Faculty of Education, University of Nigeria, Nsukka, Nigeria.

2. Department of Educational Foundations, Sociology of Education, Faculty of Education, University of Nigeria, Nsukka, Nigeria.

3. Department of Arts Education, Faculty of Education, University of Nigeria, Nsukka, Nigeria.

\section{Emails:}

Dorothy Ebere Adimora-ebere.adimora@unn.edu.ng, Eucharia Nchedo Aye -eucharia.aye@unn.edu.ng, Immaculata Nwakaego Akaneme-immaculata.akaneme@unn.edu.ng, Edith Nwakaego Nwokenna-edith.nwokenna@unn.edu.ng, Francis Ekenechukwu Akubuilo-francis.akubuilo@unn.edu.ng.

\begin{abstract}
Background: Self-esteem is a major psychological health issue. People living with HIV and AIDS have been found to be victims of discrimination and stigmatization which affect their self-esteem.

Objectives: The study investigated the influence of stigma and discrimination on self-esteem of people living with HIV and AIDS (PLHIV).

Methods: The design was a cross-sectional study carried out in four teaching hospitals in south-eastern Nigeria between 13th July 2016 - 11th May 2017. Four hundred and eighty-four (174 males and 310 females) PLHIV participated in the study. Quantitative study supplemented by qualitative in-depth interviews were used to collect data regarding discrimination, stigma and self-esteem of PLHIV whilst a structured questionnaire was used to elicit information about the socio-demographic variables.

Results: Stigmatization and discrimination were found to have significant influence on self-esteem of PLHIV. The results indicate that stigmatization and discrimination, together with income, work status, AIDS diagnosis status, and medication use status significantly influence self-esteem of PLHIV. These results imply that stigmatization and discrimination influences on self-esteem among PLHIV.

Conclusion: Conclusively, intervention programmes should evolve enlightenment through television, movies, and educational programs that incorporate the ill effects of discrimination and stigma so as to boost self-esteem of PLHIV.
\end{abstract}

Keywords: Intervention; psychological health; poverty; pocial isolation.

DOI: https://dx.doi.org/10.4314/ahs.v19i4.39

Cite as: Adimora DE, Aye EN, Akaneme IN, Nwokenna EN, Akubuilo FE. Stigmatization and discrimination as predictors of self-esteem of people living with HIV and AIDS in Nigeria. Afri Health Sci.2019;19(4):3160-3171. bttps://dx.doi.org/10.4314/abs. v19i4.39

\section{Corresponding author:}

Dorothy Ebere Adimora,

Department of Educational Foundations,

Educational Psychology, Faculty of Education,

University of Nigeria, Nsukka, Nigeria.

Email: ebere4jesus@yahoo.com

\section{Introduction}

Every individual is desirous of happy and healthy life, free from diseases. Regrettably, this has been difficult to achieve. For instance, in Nigeria, the burden of HIV and AIDS continues to increase with 3.4 million persons living with the virus as at 2014. This represents $4.1 \%$ national prevalence rate, the second largest in the world ${ }^{1}$. 
Nigeria is the second country with the largest number of people living with HIV (PLHIV) after South Africa ${ }^{2}$. HIV and AIDS remains a major public health concern in the world. HIV which stands for human immunodeficiency virus leads to the disease AIDS (acquired immunodeficiency syndrome), if left untreated. According to 3 no effective cure for HIV currently exists, but with proper treatment and medical care, HIV can be managed. This is possible with antiretroviral drugs or antiretroviral therapy (ART) which are the combination of medications used for the treatment or management of HIV and AIDS and some other chronic illnesses.

In the recent time, AIDS has become a threatening disease especially to many Nigerians who are unaware of the myth behind HIV and AIDS. This makes them avoid or stigmatize the victims believing that one contracts it by associating with or having close contact with the victim ${ }^{2}$. Stigma and discrimination according to ${ }^{3}$ are social constraints which have significant impact on the life experiences of people. HIV and AIDS stigma seems to isolate people from the community and affect the overall quality of life of PLHIV ${ }^{4}$. Stigma oftentimes is applied to social disgrace 5 . It was found that participants who reported high levels of stigma were over four times more likely to report poor access to care ${ }^{6}$. Self-stigma, or internalised stigma has an equally damaging effect on the mental wellbeing of PLHIV ${ }^{7}$. HIV and AIDS-related stigma can lead to discrimination, for example, when PLHIV are prohibited from travelling, using healthcare facilities or seeking employment, associating with people ${ }^{8}$.

According to ${ }^{9,10}$ the three types of stigma are: felt, enacted and reverse stigma. Felt stigma is the internalized perception of being devalued or "not as good as" by an individual. Enacted stigma is an act of discrimination abuse or ostracism. Reverse stigma is the act of trying to feel good by suppressing trauma. AIDS stigma by association with someone who is HIV positive is classified as secondary stigma or "courtesy stigma" which can affect family and friends of PLHIV, as well as health care workers, stigma includes prejudice and can result in active discrimination directed towards the social groups and persons to whom they are linked ${ }^{13}$. Discrimination against PLHIV is the experience of prejudice against PLHIV which falls within the purview of the law ${ }^{14}$. HIV and AIDS discrimination exists around the world in form of ostracism, rejection and avoidance. Some people are shunned by family, peers and the wider community, while others face poor treatment in healthcare and educational settings, erosion of their rights, and psychological damage. The PLHIV Stigma Index indicates that roughly one in every eight-people living with HIV is being denied health services because of stigma and discrimination 15. Consequences of stigma and discrimination are wide-ranging and may result in low turn-out for HIV counselling and testing, identity crises, isolation, loneliness, low self-esteem and lack of interest in managing the dsease ${ }^{15}$.

Healthcare professionals can medically assist HIV infected or affected person, and also provide life-saving information on how to prevent it but oftentimes, they are not confidential about a person's HIV status, behaviour, sexual orientation or gender identity ${ }^{16}$. These views are as a result of ignorance about HIV transmission routes among healthcare professionals ${ }^{17}$. Consequently, this prevents many people from being honest to healthcare workers when they seek medical help. They fear discrimination if they say they are sex workers, have same-sex relations, or inject drugs ${ }^{18}$.

In the workplace, at home or in any social setting, PLHIV suffer stigma from their co-workers and employers, such as social isolation and ridicule, or experience discriminatory practices, such as termination or refusal of employment ${ }^{19}$. A global study found that $35 \%$ of participants feared losing family and friends if they disclose their HIV status ${ }^{20}$. Research reveals that perceived and internalized stigma may result in mental disorders like depression, low self-esteem, isolation and feeling of hopelessness or loss of control which can ultimately result in loss of motivation to remain in care and non-adherence to treatment and even suicidal inten $\mathrm{ts}^{21}$.

However, self-esteem is the confidence in one's ability to think, cope with the challenges of life and a recognition of being worthy of happiness and success. Self-esteem refers to how much people value themselves; the pride they feel in themselves, and how worthwhile they feel ${ }^{22}$. Furthermore, trusting one's mind and being aware that one is worthy of greatness is therefore, the very essence of self-esteem. Self-esteem can be shaped by both internal and external factors; from within an individual, how one treats oneself or self-talk, and from outside of an individual, such as from the environment in which one lives, works and people whom one sees and interacts with. The ability to feel valuable, special, worthwhile, needed, im- 
portant or feel good, raises the level of self-esteem which is referred to as high self-esteem, but the things that make one feel bad, self-doubt, rejection or criticism lower the feeling of self-worth and create low self-esteem ${ }^{22}$. A person who has high self-esteem makes friends easily, feels more acceptable in the society, is more in control of his or her behaviour, and enjoys life more ${ }^{22}$. Stigmatization and discrimination of PLHIV have been linked to low self-esteem which is detrimental to an individual's wellbeing.

\section{Current study}

The study was mainly an exploratory study because no such study has been carried out in the South-Eastern Nigeria using the four recognized teaching hospitals.

\section{Aims and objectives of the study}

The main aim of the study was to investigate the influence of stigma and discrimination on self-esteem of people living with HIV and AIDS. Specifically, the study ascertained the influence of sociodemographic variables and stigma on self-esteem of PLHIV. It also determined the influence of sociodemographic variables and discrimination on self-esteem of PLHIV.

\section{Materials and methods}

\section{Research design}

This study is a cross-sectional study carried out between 13th July 2016 - 11th May 2017. The researchers used quantitative study supplemented by qualitative in-depth interviews to collect relevant information regarding discrimination, stigma and their self-esteem whilst a structured questionnaire was used to collect data on the socio-demographic variables.

\section{Sample population}

At the four hospitals used for this study, medical records were reviewed to recruit the potential participants who eventually participated in the study. The name of the hospitals used for the study and the potential participants who were later sampled according to those who gave their consent to participate in the study include: University of Nigeria Teaching Hospital, Enugu- 488, Abia State University Teaching Hospital-255, Federal Teaching Hospital, Abakiliki, Ebonyi State- 292, and Nnamdi Azikiwe University Teaching Hospital, Nnewi- 282, making a total of 1317 PLHIV in four teaching hospitals in South-Eastern Nigeria.

\section{Sampling methodology}

The participants were 484 (174 male and 310 female) people living with HIV and AIDS drawn through purposive sampling of HIV patients who have anonymously accepted to be used for the study. There was no need to apply other sampling techniques since only those who anonymously accepted to participate in the study were used for the study.

\section{Reliability}

Reliability of the interview questions and the questionnaire item statements were ascertained before the main study in University of Port-Harcourt Teaching Hospital (UPTH) which was not part of this study, and the reliability coefficient score was revealed. Data collected was analysed using Cronbach alpha and a coefficient of consistency of 0.82 was established. A test-retest reliability to determine the stability of the instrument overtime was conducted.

\section{Inclusion and exclusion criteria}

Participation was voluntary, informed verbal consent was obtained from the PLHIV before they were included in the study. The selection was made from the participants who were visiting the hospital at the time of this research and adhere to medications and medical appointments.

\section{Measures}

\section{Socio-demographic data}

The socio-demographic data in this study were age, gender, ethnic grouping, education, adequacy of income, work status, AIDS diagnosis and antiretroviral medication use.

\section{HIV-related stigma}

HIV-related stigma was ascertained using the PLHIV Stigma Index Questionnaire. The stigma index questionnaire is the primary research tool that was used for quantitative data collection from the study respondents for measuring HIV related stigma and discrimination among people living with HIV. The tool comprised stigma and discrimination in different settings such as home, community, workplace, religious and healthcare settings. The participants were told to respond to the questionnaire based on their experiences.

Participants indicated the extent to which the attribute of being HIV positive is perceived negatively by various individuals in their social settings. Statements were respond- 
ed to four-point format: very high extent, high extent, low extent and very low extent. Items include: "Some of my friends have abandoned me because I disclosed my HIV positive status to them" "Oftentimes, people desist from touching me because they noticed that I am HIV positive." Personalized stigma scores were calculated by finding the total scores for the items. Internal consistency was originally established (range from 0.85 to 0.92 ) with a sample of Nigerians living with HIV. The test-retest reliability ranged from 0.87 to 0.90 with 3 weeks between tests. For the purpose of this study, reliability showed a good internal consistency of items Cronbach's alpha $(\alpha=$ $0.85)$. Its negative relationship to self-esteem $(r=-0.35$, $\mathrm{P}<0.01)$ reveals its construct validity. At the end of the study, it was revealed that $87 \%$ of participants were stigmatized.

\section{Discrimination}

A four-item anticipated discrimination was developed and administered to the respondents. Initially, before the main study, focus group discussion with 10 volunteered PLHIV was conducted purposely to identify and relate what they perceived as discrimination from cultural perspective. Discussions generated centre on friendship, likeness, isolation, and distance. Ten items were generated from the responses of PLHIV into a scale and administered to another set of PLHIV in another area. The items include: "Do people who know about your HIV and AIDS positive status want to be friends with you?" Does having HIV and AIDS affect you being invited to go out on dates or attend a party" For each item, subjects are asked to respond on a four-point scale: Oftentimes ${ }^{9}$, sometimes, seldom, and never. The researchers conducted an exploratory common factor analysis on the ten items. A principal component factor analysis with varimax rotation yielded 1 factor (anticipated discrimination). The goodness-of-fit statistic was $56.21(\mathrm{P}=0.003)$, suggesting that the one-factor model provided an adequate fit. All loadings were above the acceptable Eigenvalue of 0.470 and accounted for $61 \%$ of the total variance. Reliability showed a good internal consistency of items Cronbach's alpha $(\alpha=0.78)$. At the end of the study, $83 \%$ of the participants were found to have experienced discrimination.

\section{Self-esteem}

Rosenberg self-esteem (RSE) scale (Rosenberg, 1965) of 10 items was used to assess their self-esteem. The RSE scale is a 10-item related to feelings of self-worth or self-acceptance and competence. It measures self-esteem in line with stigmatization and discrimination ${ }^{23}$. The items stated include "On the whole, I am satisfied with myself." Respondents express their degree of agreement on a 4-point Likert-type scale of strongly agree $=4$, agree $=3$, disagree $=2$, and strongly disagree $=1$. This scale rubrics range from 10 (low self-esteem) to 40 (high self-esteem). Cronbach's alpha reliability coefficient for the scale in this study was 0.84 . The scale generally has high reliability: Test-retest correlations are in the range of $0.74-0.89$. The extracted factors are in line with that reported by Rosenberg. All items had a factor loading of 0.4 Eigenvalue. Coefficient alpha was 0.92 . The present sample reported a coefficient alpha of $\alpha=0.87$. No norms or cut-off were found for non-clinical samples. ${ }^{24}$ reported RSES scores $(M=32.21$; $S D=5.01)$ in a US college student sample $(\mathrm{N}=2782)$. Similar scores were reported for men $(\mathrm{M}=32.43$; $\mathrm{SD}=6.21)$ and women $(\mathrm{M}=32.79$; $\mathrm{SD}$ $=5.41)$ in a study with diverse national adult sample ${ }^{25}$. The one study in PLHIV that reported their item-scoring rubric described RSES scores $(M=30.46$; $S D=4.75)$ in a small sample of Hispanic men ${ }^{26}$. At the end of the study, $92 \%$ of the participants were found to had experienced low self-esteem.

\section{Data analysis and methods}

The participants were requested to complete a paper-pencil version of the measures. The quantitative data were collected by eight health professionals with a first degree as their qualification after two days of training to familiarize them with the techniques of in-depth interviews. The names in the questionnaires were replaced by codes and participants were informed for a record of their own codes to facilitate tracking of the completeness of their respective questionnaires. The completeness of the data was checked on site and the codes for the incomplete questionnaires were posted for the participants. Field practice was carried out on the skills of interviewing and transcribing verbatim.

The socio-demographic characteristics (gender, age, ethnicity, education, income adequacy, work status, AIDS diagnosis, currently taking retroviral medication) of the participants were analysed using descriptive statistics. A list of answers to these socio-demographic variables were elaborated which enabled to interpret the data obtained in a more adequate way. 
Additionally, linear regression analyses were performed. The linear regression was used to determine the influence of stigmatization and discrimination on self-esteem. This analysis was done as a single model where both the scores of stigmatization and discrimination were entered at the same time into the model as the predictors, while self-esteem scores were entered into the model as the outcome variable. Furthermore, one-way analysis of variance was performed to determine the influence of stigmatization and discrimination on self-esteem by considering the socio-demographic characteristics (control variables).

Contact summaries were written in English for each interview. The analysis primarily focused on data collected in the form of expanded field notes of recorded interviews. Images and sounds such as facial expressions, promptness or reluctance in responding to questions, emphatic nature of the responses, and frustrations in addressing certain issues were also systematically interpreted and their meanings noted on paper and incorporated into the analysis. Data reduction was performed to get the overall sense of the data collected, to separate the essential from the non-essential. To understand how the key domains were organized into a framework, the researchers examined quotes and described the predictive power of stigma and discrimination on self-esteem. Examples of the interview questions include: Do you freely disclose your HIV status? Do you associate with people freely without fear of being stigmatized? Do you disclose your status without fear of breakage or fear of dissolution of relationship?

\section{Ethical consideration/approval}

The study was approved by the Research Ethical Committee of University of Nigeria, Nsukka ethical clearance committee. This clearance granted the researchers the permission to visit the four teaching hospitals used for the study and also gave them access to the management of the hospitals and their respondents. Verbal and written consent were obtained from each participant prior to data collection. Privacy and confidentiality were maintained throughout the study. Subsequently, each prospective respondent was approached by the researchers and the purpose and demands of the study were explained. They were informed that participation was voluntary and were assured of anonymity and confidentiality of information before informed consent was obtained. The researchers assisted those who needed help to complete the questionnaire.

\section{Results}

Table 1: Socio-demographic characteristics of the participants

\begin{tabular}{llll}
\hline Variables & Categories & Frequency & Percent \\
\hline Gender & Male & 174 & 36.0 \\
& Female & 310 & 64.0 \\
Age (in years) & $18-29$ & 91 & 18.8 \\
& $30-44$ & 298 & 61.6 \\
& $45-59$ & 83 & 17.1 \\
Ethnicity & 60 \& above & 12 & 2.5 \\
& Igbo & 411 & 84.9 \\
& Hausa & 38 & 7.9 \\
Education & Yoruba & 35 & 7.2 \\
& Less than High School & 161 & 33.3 \\
& High School & 106 & 21.9 \\
& University Education/Equivalent & 136 & 28.1 \\
& Master's Degree & 50 & 10.3 \\
Income & Doctorate Degree & 31 & 6.4 \\
Adequacy & Totally Inadequate & 342 & 70.7 \\
& & & \\
Work Status & Barely Adequate & 105 & 21.7 \\
& Adequate & 37 & 7.6 \\
AIDS Diagnosis & Work for Pay & 160 & 33.1 \\
& Do not Work for Pay & 324 & 66.9 \\
& Yes & 380 & 78.5 \\
Currently taking & No & 75 & 15.5 \\
Antiretroviral & Yes not Know & 29 & 6.0 \\
Medication & No & 184 & 38.0 \\
& & 300 & 62.0 \\
& & & \\
\hline
\end{tabular}


Table 1 shows the socio-demographic characteristics of the study sample according to gender, age, ethnicity, education, income adequacy, work status, AIDS diagnosis and antiretroviral medication use. The sample of this study included a total of $174(36.0 \%)$ male and 310 (64.0\%) female (64\%) participants. By age, 91 (18.8) participants were in the age range of 18-29years; 298 (61.6\%) were in the age range of $30-44$ years; $83(17.1 \%)$ were in the age range of $45-59$ years; and $12(2.5 \%)$ participants were 60 years and above. Based on ethnicity, 411 (84.9\%) participants were Igbo; 38 (7.9) were Hausa; while 35 $(7.2 \%)$ were Yoruba. By education, up to $161(33.3 \%)$ had qualifications less than high school; $106(21.9 \%)$ had high school qualifications; $136(28.1 \%)$ had university education or its equivalent; $50(10.3 \%)$ had master's degree; while 31 (6.4\%) had doctorate degree. Based on income adequacy, $342(70.7 \%)$ participants had totally inadequate income; $105(21.7 \%)$ had barely adequate income; and 37 $(7.6 \%)$ had adequate income. By work status, those who work for pay were 160 (33.1\%), while those who do not work for pay were 324 (66.9\%). Regarding their AIDS diagnosis status, $380(78.5 \%)$ participants indicated a "yes"; $75(15.5 \%)$ indicated "no", while $29(6.0 \%)$ indicated "do not know." With respect to currently taking antiretroviral medication, $184(38.0 \%)$ indicated a "yes" while 300 $(62.0 \%)$ indicated "no".

Table 2:

\begin{tabular}{|c|c|c|c|c|c|c|c|c|c|c|}
\hline \multirow[b]{2}{*}{ Variables } & \multirow[b]{2}{*}{ Categories } & \multicolumn{3}{|l|}{ Stigmatization } & \multicolumn{3}{|c|}{ Discrimination } & \multicolumn{3}{|l|}{ Self-esteem } \\
\hline & & $\mathrm{M} \pm \mathrm{SD}$ & $F$ & $P$ & $\mathrm{M} \pm \mathrm{SD}$ & $F$ & $P$ & $\mathrm{M} \pm \mathrm{SD}$ & $F$ & $P$ \\
\hline \multirow[t]{2}{*}{ Gender } & Male & $41.24 \pm 12.38$ & 1.112 & .292 & $25.45 \pm 8.03$ & 1.710 & .192 & $20.53 \pm 7.31$ & .030 & .863 \\
\hline & Female & $42.42 \pm 11.59$ & & & $26.41 \pm 7.49$ & & & $20.40 \pm 8.44$ & & \\
\hline \multirow[t]{4}{*}{ Age (in years) } & $18-29$ & $39.02 \pm 13.28$ & & & $24.74 \pm 7.99$ & & & $21.10 \pm 6.71$ & & \\
\hline & $30-44$ & $41.97 \pm 11.34$ & 4.544 & .004 & $26.20 \pm 7.71$ & 3.044 & .029 & $20.22 \pm 7.92$ & .895 & .443 \\
\hline & $45-59$ & $44.28 \pm 12.11$ & & & $26.22 \pm 7.42$ & & & $20.96 \pm 10.08$ & & \\
\hline & $60 \&$ above & $49.33 \pm 4.42$ & & & $31.58 \pm 3.89$ & & & $17.58 \pm 3.06$ & & \\
\hline \multirow[t]{3}{*}{ Ethnicity } & Igbo & $41.55 \pm 11.75$ & 12.679 & .000 & $25.93 \pm 7.72$ & 8.631 & .000 & $20.35 \pm 7.79$ & 15.696 & .000 \\
\hline & Hausa & $38.53 \pm 14.25$ & & & $23.34 \pm 8.68$ & & & $25.89 \pm 10.46$ & & \\
\hline & Yoruba & $51.06 \pm 4.32$ & & & $30.54 \pm 3.41$ & & & $15.71 \pm 3.66$ & & \\
\hline \multirow[t]{7}{*}{ Education } & Less than High & $40.55 \pm 12.85$ & 7.248 & .000 & $25.58 \pm 8.16$ & 3.679 & .006 & $20.50 \pm 6.68$ & 6.548 & .000 \\
\hline & School & & & & & & & & & \\
\hline & High School & $43.19 \pm 10.78$ & & & $26.78 \pm 7.42$ & & & $19.08 \pm 7.44$ & & \\
\hline & University & $40.35 \pm 11.67$ & & & $25.23 \pm 7.76$ & & & $21.60 \pm 9.04$ & & \\
\hline & Education/Equivalent & & & & & & & & & \\
\hline & Master's Degree & $42.48 \pm 11.84$ & & & $25.54 \pm 7.61$ & & & $23.30 \pm 10.38$ & & \\
\hline & Doctorate Degree & $51.87 \pm 3.72$ & & & $30.65 \pm 3.28$ & & & $15.26 \pm 3.52$ & & \\
\hline \multirow{3}{*}{$\begin{array}{l}\text { Income } \\
\text { Adequacy }\end{array}$} & Totally Inadequate & $42.06 \pm 11.80$ & 16.660 & .000 & $26.29 \pm 7.76$ & 11.813 & .000 & $19.52 \pm 6.957$ & 29.767 & .000 \\
\hline & Barely Adequate & $38.54 \pm 12.25$ & & & $23.73 \pm 7.79$ & & & $25.15 \pm 10.20$ & & \\
\hline & Adequate & $51.24 \pm 4.27$ & & & $30.57 \pm 3.35$ & & & $15.73 \pm 3.68$ & & \\
\hline \multirow[t]{2}{*}{ Work Status } & Work for Pay & $40.85 \pm 12.89$ & 2.229 & .136 & $25.74 \pm 8.19$ & .430 & .512 & $20.08 \pm 6.82$ & .503 & .497 \\
\hline & Do not Work for Pay & $42.56 \pm 11.32$ & & & $26.23 \pm 7.44$ & & & $20.63 \pm 8.59$ & & \\
\hline \multirow{3}{*}{$\begin{array}{l}\text { AIDS } \\
\text { Diagnosis }\end{array}$} & Yes & $40.01 \pm 13.34$ & 10.342 & .000 & $25.31 \pm 8.02$ & 5.852 & .003 & $20.53 \pm 6.58$ & 7.124 & .001 \\
\hline & No & $41.68 \pm 11.68$ & & & $25.86 \pm 7.76$ & & & $20.84 \pm 8.41$ & & \\
\hline & Do not Know & $51.24 \pm 4.35$ & & & $30.69 \pm 3.51$ & & & $15.07 \pm 3.53$ & & \\
\hline \multirow{2}{*}{$\begin{array}{l}\text { Currently } \\
\text { taking } \\
\text { Antiretroviral } \\
\text { Medication }\end{array}$} & Yes & $40.00 \pm 12.75$ & 8.507 & .004 & $25.04 \pm 8.26$ & 5.269 & .022 & $21.21 \pm 6.99$ & 2.631 & .105 \\
\hline & No & $43.22 \pm 11.16$ & & & $26.69 \pm 7.27$ & & & $19.99 \pm 8.61$ & & \\
\hline
\end{tabular}

Table 2: shows the mean difference in stigmatization, discrimination and self-esteem scores of PLHIV according to socio-demographic variables.

By gender, there was no significant difference for stigmatization $(p=.292)$, discrimination $(p=.192)$, and self-esteem $(p=.863)$ among PLHIV. There were significant differences across age groups for stigmatization $(p=.004)$, and discrimination $(\mathrm{p}=.029)$, but not for self-esteem $(\mathrm{p}=$ .443). The test for differences by ethnicity revealed that there were significant differences for stigmatization $(\mathrm{p}=$ $.000)$, discrimination $(p=.000)$, and self-esteem $(p=.000)$ among PLHIV. There were significant differences for stigmatization $(p=.000)$, discrimination $(p=.006)$, and self-esteem $(p=.000)$ among PLHIV with regard to education. In terms of income adequacy, there were significant differences for stigmatization $(p=.000)$, discrimination $(p=.000)$, and self-esteem $(p=.000)$ among PLHIV. By work status, there was no significant difference for 
stigmatization $(\mathrm{p}=.136)$, discrimination $(\mathrm{p}=.512)$, and self-esteem $(p=.497)$ among PLHIV. Based on AIDS diagnosis, there were significant differences for stigmatization $(p=.000)$, discrimination $(p=.003)$, and self-esteem $(\mathrm{p}=.001)$ among PLHIV. With regard to those currently or not currently taking antiretroviral medication, there were significant differences for stigmatization $(p=.004)$, and discrimination $(\mathrm{p}=.022)$, but not for self-esteem $(\mathrm{p}=$ $.105)$.

Table 3: Multiple regression of stigmatization and discrimination on self-esteem

\begin{tabular}{llccc}
\hline Predictor & Outcome & $\mathrm{R}^{2}$ & Adj. $\mathrm{R}^{2}$ & $\beta$ \\
\hline & Self-esteem & .702 & .701 & \\
Stigmatization & & & & $-.488^{* * *}$ \\
Discrimination & & & & $-.396^{* * *}$ \\
\hline
\end{tabular}

Note: $\mathrm{F}(2,481)=566.3, * * * \mathrm{p}<.001$

Table 3 depicts a model of multiple regression of stigmatization and discrimination influencing self-esteem of PLHIV. The table depicts that the regression estimates of stigmatization $(\beta=-.488, \mathrm{p}<.001)$ was significant. The table also depicts that the regression estimates of discrimination $(\beta=-.396, p<.001)$ was significant. The adjusted
R-square reveals that $70.1 \%$ of influence on self-esteem was caused by stigmatization and discrimination. These results imply that stigmatization and discrimination have significant influence on self-esteem of PLHIV. In addition, Figure 1 shows a conceptual model of this study in accordance with the findings.

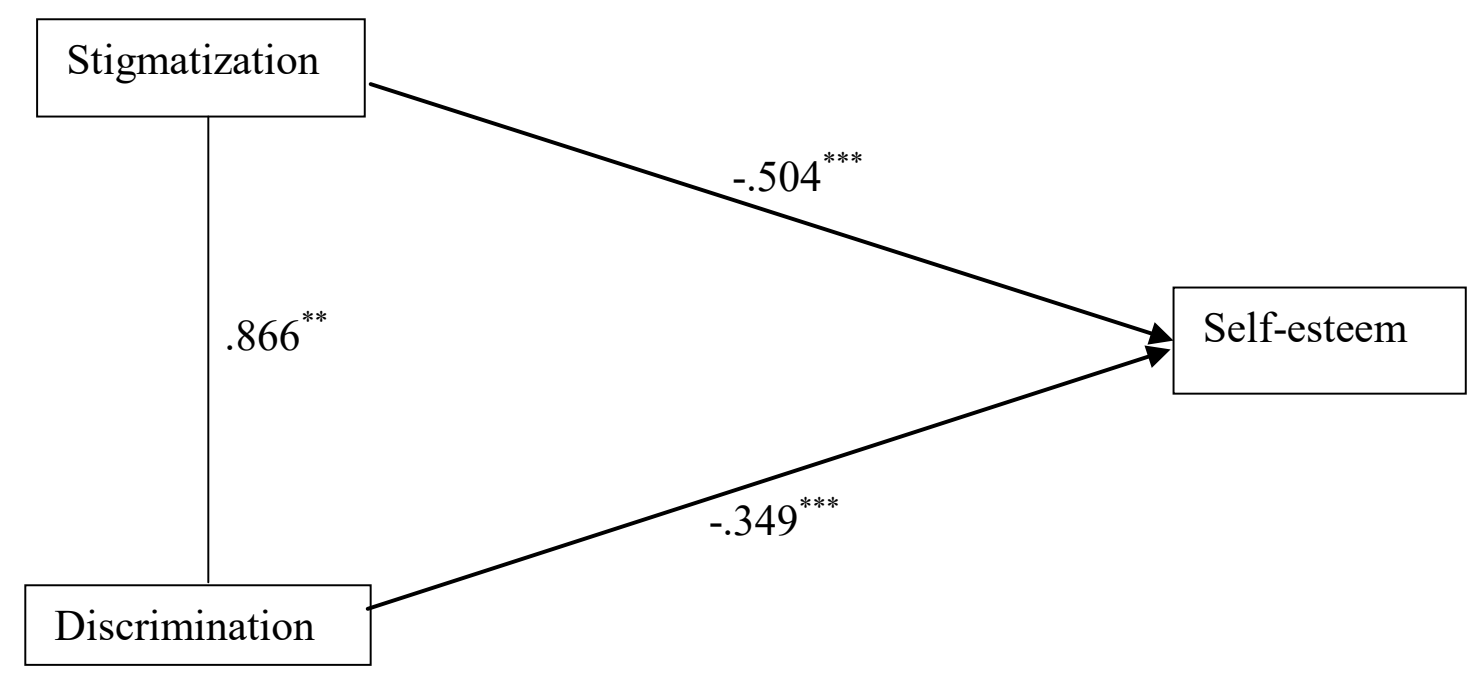

Fig 1: Conceptual Model of the Study $\left({ }^{* * *} \mathrm{p}<.001 ;{ }^{* *} \mathrm{p}<.01\right)$. 
Table 4: shows the influence of stigmatization and discrimination on self-esteem of PLHIV by socio-demographic variables.

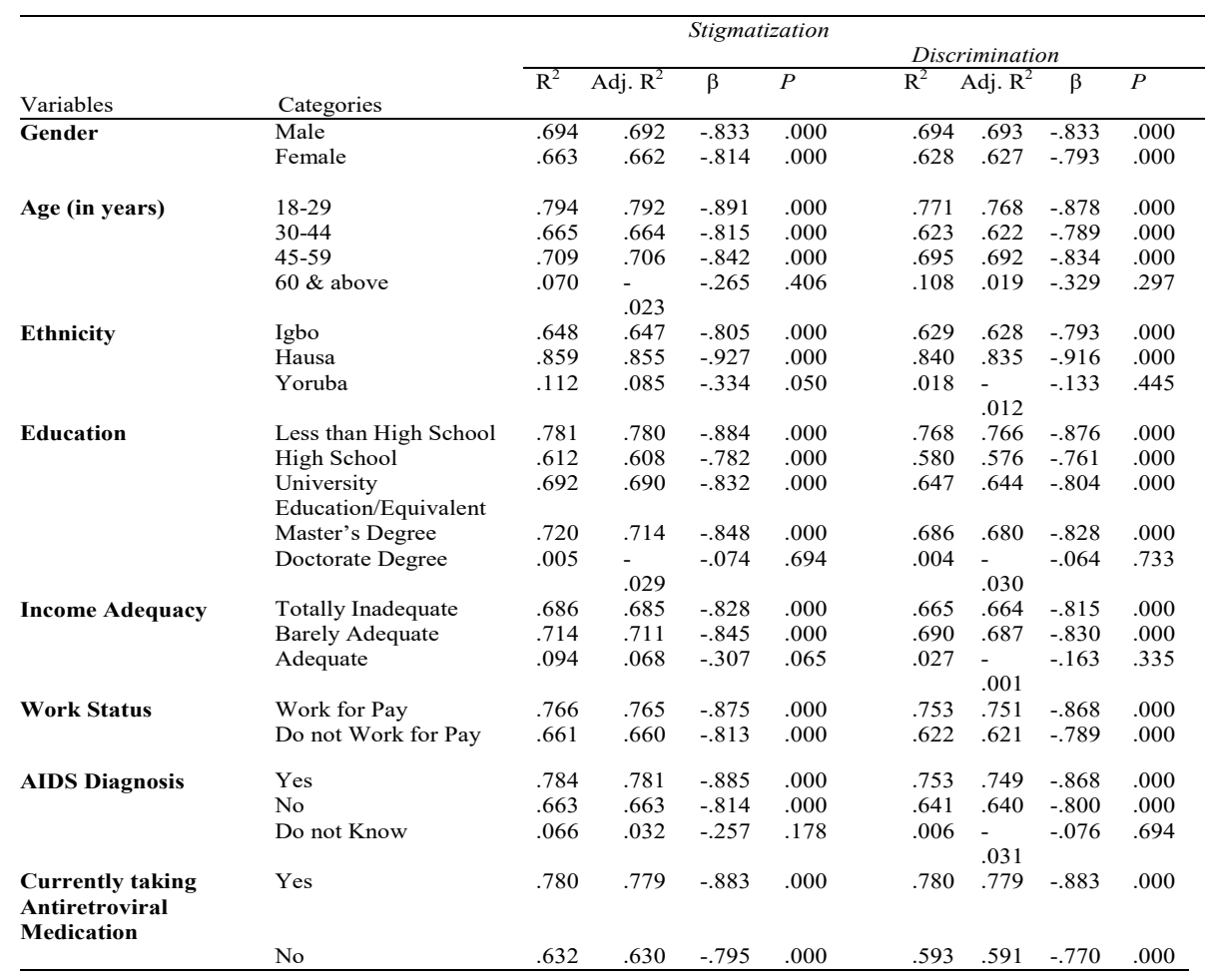

Table 4: shows the influence of stigmatization and discrimination on self-esteem of PLHIV by socio-demographic variables.

By gender, stigmatization had significant influence on self-esteem of both male $(\beta=-.833, p=.000)$ and female $(\beta=-.814, p=.000)$ PLHIV. Likewise, discrimination had significant influence on self-esteem of both male $(\beta=$ .833, $\mathrm{p}=.000)$ and female $(\beta=-.793, \mathrm{p}=.000)$ PLHIV. Therefore, irrespective of gender, both stigmatization and discrimination significantly influence the self-esteem of PLHIV.

By age, stigmatization had significant influence on self-esteem of PLHIV who were 18-29years $(\beta=-.891, \mathrm{p}=.000)$, 30-44years $(\beta=-.815, p=.000)$, and 45-59years $(\beta=-.842$, $\mathrm{p}=.000)$ but had no significant influence on those who were 60years and above $(\beta=-.265, p=.406)$. In the same way, discrimination had significant influence on self-esteem of PLHIV who were 18-29years $(\beta=-.878, p=.000)$, 30-44years $(\beta=-.789, p=.000)$ and $45-59$ years $(\beta=-.834$, $\mathrm{p}=.000)$ but had no significant influence on those who were 60years and above $(\beta=-.329, \mathrm{p}=.297)$. These results suggest that the effect of discrimination and stigmatization on self-esteem of PLHIV might become less significant as they get older.
With respect to ethnicity, stigmatization had significant influence on self-esteem of PLHIV belonging to Igbo $(\beta=-.805, p=.000)$, Hausa $(\beta=-.927, p=.000)$, and Yoruba $(\beta=-.334, p=.050)$ ethnic groups. However, discrimination had significant influence on self-esteem of PLHIV belonging to Igbo $(\beta=-.793, p=.000)$, and Hausa $(\beta=$ $.916, \mathrm{p}=.000)$ ethnic groups, but did not have significant influence on self-esteem of PLHIV belonging to the Yoruba ethnic group $(\beta=-.133, p=.445)$. This suggests that while stigmatization is a significant factor influencing the self-esteem of PLHIV despite their ethnicity, it might not be so with discrimination. As found, discrimination significantly influenced the self-esteem of PLHIV belonging to Igbo and Hausa ethnicity but not those from Yoruba.

By education, stigmatization had significant influence on self-esteem of PLHIV with qualifications less than high school $(\beta=-.884, p=.000)$, those with high school $(\beta=-$ $.782, p=.000)$, university education or its equivalent $(\beta=$ $.832, \mathrm{p}=.000)$, and master's degree $(\beta=-.848, \mathrm{p}=.000)$, but had no such influence on those with doctorate degree $(\beta=-.074, p=.694)$. Also, discrimination had significant influence on self-esteem of PLHIV with qualifications less than high school $(\beta=-.876, p=.000)$, those with high 
school $(\beta=-.761, p=.000)$, university education or its equivalent $(\beta=-.804, p=.000)$, and master's degree $(\beta=-$ $.828, \mathrm{p}=.000)$, but had no such influence the self-esteem of those with doctorate degree $(\beta=-.064, p=.733)$. Thus, it seems that higher education serves as a protective factor against the effects that stigmatization and discrimination would have on the self-esteem of PLHIV.

By income adequacy, stigmatization had significant influence on self-esteem of PLHIV whose income was totally inadequate $(\beta=-.828, p=.000)$ and barely adequate $(\beta=$ $.845, \mathrm{p}=.000)$, but had no significant influence on self-esteem of PLHIV whose income was adequate $(\beta=-.307$, $\mathrm{p}=.065)$. Likewise, discrimination had significant influence on self-esteem of PLHIV whose income was totally inadequate $(\beta=-.815, p=.000)$ and barely adequate $(\beta=$ $.830, \mathrm{p}=.000)$, but had no significant influence on self-esteem of PLHIV whose income was adequate $(\beta=-.163$, $\mathrm{p}=.335)$. These results suggest that income adequacy might help minimize the effects that stigmatization and discrimination would have on the self-esteem of PLHIV. As demonstrated, stigmatization and discrimination did not significantly influence the self-esteem of PLHIV who had adequate income.

Based on work status, stigmatizatio6n had significant influence on self-esteem of PLHIV who work for pay $(\beta=$ $.875, p=.000)$ and those who do not work for pay $(\beta=-$ $.813, \mathrm{p}=.000)$. Discrimination had significant influence on self-esteem of PLHIV who work for pay $(\beta=-.868$, $\mathrm{p}=.000)$ and those who do not work for pay $(\beta=-.789$, $\mathrm{p}=.000)$. Thus, whether PLHIV are engaged in paid or unpaid work, stigmatization and discrimination signiicantly influence their self-esteem.

By AIDS diagnosis status, stigmatization had significant influence on self-esteem of PLHIV who indicated a "yes" $(\beta=-.885, p=.000)$ and those who indicated "no" $(\beta=-.814, p=.000)$, but had no significant influence on the self-esteem of PLHIV who indicated "do not know" $(\beta=-.257, p=.178)$. Similarly, discrimination had significant influence on self-esteem of PLHIV who indicated a "yes" $(\beta=-.868, p=.000)$ and those who indicated "no" $(\beta=-800, p=.000)$, but had no significant influence on the self-esteem of PLHIV who indicated "do not know" $(\beta=-.076, p=.694)$. This suggests that the self-esteem of PLHIV who do not know their AIDS diagnosis status ap- pears not to be significantly influenced by stigmatization and discrimination unlike their counterparts.

With respect to those currently or not currently taking antiretroviral medication, stigmatization had significant influence on self-esteem of PLHIV who were currently taking antiretroviral medication $(\beta=-.883, p=.000)$ and not currently taking antiretroviral medication $(\beta=-.795$, $\mathrm{p}=.000)$. Finally, discrimination had significant influence on self-esteem of PLHIV who were currently taking antiretroviral medication $(\beta=-.883, \mathrm{p}=.000)$ and not currently taking antiretroviral medication $(\beta=-.770, \mathrm{p}=.000)$. Therefore, whether PLHIV are currently or not currently taking antiretroviral medication, stigmatization and discrimination have significant influence on their self-esteem.

\section{Discussion}

The findings of this study reveal our participants as predominantly females. They comprised $64.0 \%$ females and 36.0 males. This agrees with the report National HIV and AIDS and reproductive health services ${ }^{25}$ of higher prevalence among women due to higher vulnerability and infections in all age groups. One of the key drivers in HIV distribution is the entrenched danger of inequalities and inequities. This is mostly prevalent in the areas of economic dependency for women, because in most societies, men have greater control and access to productive resources ${ }^{26}$. As a result of this, women do not have right to determine sex choice or right over their body. For instance, in sub-Saharan Africa, 61\% of PLHIV are wom$\mathrm{en}^{27}$. Similarly, reports have shown that a young woman in Africa is up to eight times more likely to acquire HIV than a young $\operatorname{man}^{14}$. In Nigeria, HIV prevalence rate in females is $4.0 \%$ compared to $3.2 \%$ in men.

This study also reveals highest prevalence of HIV in the age range $30-44$ years corresponding to the 28 reports that HIV and AIDS was highest in the age range 30-34 years in the urban region. This was also established in the HIV and AIDS prevalence in the age group 30-44 in both males and females in consonance with the results obtained. This study indicated that the Igbos who participated in the study were $85 \%$ whilst Hausa $(8 \%)$ and Yoruba $(7 \%)$. The study was carried out in South-eastern part of Nigeria where majority of the participants are Igbos, which resulted in the majority of Igbo participants. The cultural aspect of polygamy in Nigeria places addi- 
tional pressure on the women resulting in spread of HIV in the society. In our study, education was a vital factor that should be addressed with regard to the spread of HIV-positive subjects. The result shows that a greater percentage of our HIV respondents $(33 \%)$ were those with less than high school. This result agrees with National results report that highest prevalence of HIV in women is found among those with primary and secondary education $^{29}$. This category of people are workers and mostly commute between the villages and the city since they may not be able to maintain their families in the city. This invariably exposes them to higher sexual risk behaviour. The females in this group are not able to determine sex choice because of economic dependence on the men and societal pressure. They also have the likelihood of being uninformed about the health facilities available to them. In the paper on the stigmatization of PLHIV, ${ }^{30}$ recommended education for in-depth knowledge of HIV and AIDS from primary to tertiary institutions among others. Poverty, inadequate income and work status are also driving factors to HIV and AIDS. This explains in this study, why those with totally inadequate income (70\%) and those who do not work for pay (67\%) are major contributing factor to increased HIV prevalence. This result is in line with previously reported study in Nigeria which revealed prevalence of HIV infection among junior civil servants and the unemployed individuals ${ }^{31}$. This study reveals $38 \%$ to be on antiretroviral and $62 \%$ not receiving antiretroviral. However, obsevation, while carrying out this study indicates that a greater majority of our HIV participants have been on long-term ARV therapy.

No previous study has revealed gender differences in stigmatization, discrimination and self-esteem. A study by 32 explained that the factors tested, age, gender, education and wealth index were significantly associated with HIV stigma. Younger persons, males, those with lesser education and those in the lower income index tend to agree more that PLHIV should be ashamed of themselves and that people with HIV should be blamed for bringing the disease into the community. These findings are similar to that of several other studies. Interestingly, those with higher levels of education and in the higher wealth index are more sympathetic towards PLHIV. This could be due to higher awareness among the educated and wealthy ones on the prognosis of PLHIV and the availability of anti-retroviral treatments.
This study finds that stigmatization and discrimination exert significant influence on self-esteem of PLHIV. The results indicate that stigmatization and discrimination, together with income, work status, AIDS diagnosis status, and medication use status significantly influence self-esteem of PLHIV. This finding corroborates with19 that experienced, perceived and internalized stigma may result in mental disorders like depression, low self-esteem, isolation and feeling of hopelessness or loss of control which can ultimately result in loss of motivation to remain in care and non-adherence to treatment and even suicidal intents. Similarly,33 explained that stigma and discrimination affect self-esteem of PLHIV. The study also agrees with34 who explained that stigma and discrimination cause negative health outcomes for PLHIV which includes poor treatment adherence, engagement in unsafe sexual behaviours, greater severity of AIDS related symptoms, lower perceived general health, low self-esteem and less health care satisfaction.

\section{Limitations}

The cross-sectional design used in this study precludes our ability to make inferences about causality. The design along with convenience sampling, and the self-report nature of the data may also bias study results. Also, some participants due to shame, fear and lack of confidence, seemed not to have revealed the actual state of their mind and experiences.

\section{Conclusion}

The negative sequelae of low self-esteem in PLHIV are well documented. This descriptive cross-sectional study is the first to examine the influence of stigmatization and discrimination on self-esteem of PLHIV in the area of this study using this population. Findings reveal that stigma and discrimination influences significantly higher the self-esteem of PLHIV. Age, gender, education, work status income inadequacy, AIDS diagnosis and retroviral medications have been perceived to collaborate with stigma and discrimination to influence the self-esteem of PLHIV. Conclusively, intervention to boost the low level of self-esteem should evolve enlightenment programme through the television,ovies in the hospitals and other places and also educational programs that incorporate discrimination and stigma. 


\section{Conflict of interest}

All the authors declare that they have no conflict of interests with the publication of this paper.

\section{References}

1. World Health Organisation (WHO) 'Global HIV/ AIDS Response: Epidemic update and health sector progress towards Universal Access: Progress report 2019'.

2. National Agency for the Control of AIDS, Update on the HIV/AIDS epidemic response in Nigeria," 2011; Retrieved from http://www.naca.gov.ng/index2.php.

3. Rzeszutek, M; Oniszczenko, W; Schier, K; Biernat-Kaluza, E and Gasik, R Temperament traits, Social Support and Trauma Symptoms among HIV/AIDS and Chronic Pain Patients. International Journal of Clinical and Health Psychology, 2016; 16, 137-146.

4. Goffman, E. Stigma, roles on the management of a spoiled identity. NJ prentice hall, Englewood cliffs 147; 1963.

5. Raheel, H. Stigma towards People Living with HIV/ AIDS (PLWAs) among Adolescents of Riyadh, Kingdom of Saudi Arabia. Journal of AIDS \& Clinical Research. 7: 612; 2016. doi:10.4172/2155-6113.1000612.

6. Hardon A, Boonmongkon P, Streefland P. Applied Health Research Manual Anthropology of Health and HealthCare. The Hague: CIP-Data, Koninklijke Bibliotheek, Netherlands; 1995.

7. Sayles, J. 'The Association of Stigma with Self-Reported Access to Medical Care and Antiretroviral Therapy Adherence in Persons Living with HIV/AIDS.' Journal of General Internal Medicine, 2009; 24(10).

8. International Center for Research on Women ICRW, 'HIV-related stigma across contexts: common at its core'. 2005; Retrieved from http//www.icrw.org/publcatios/ common-its-core-hiv-related-stigma-acrosscontexts.

9. Jacoby, A. Felt versus enacted stigma: A concept revisited. Evidence from a study of people with epilepsy in remission. Social Science \& Medicine, 1994; 269-274.

10. Block, R.G. "Is it just me? Experiences of HIV related stigma. Journal of HIV/AIDS \& Social Sciences, 2009; 8, 1-19.

11. Herek G.M, Glunt E.K. An epidemic of stigma: Public reactions to AIDS. American Psychologist, 1998; 43:886892 PubMed .

12. Herek, G.M. Thinking about AIDS and stigma: A psychologist's perspective. Journal of Law, Medicine, and Ethics, 2002; 30, 594-607 PubMed .

13. UNAIDS. 'On the Fast-Track to end AIDS by 2030:
Focus on location and population'. 2015; Retrieved from http://www.unaids.org/sites/default/files/media-asset/ wad.2015report.

14. The Lancet 'HIV: science and stigma'; 2015. Retrieved from http://www.thelancet.com/journals/lancet/article/piis0140.

15. Stutterheim, S.E. 'HIV-related stigma and psychological distress: the harmful effects of specific stigma manifestations in various social settings', 2009; AIDS 23:17. 16. Human Rights Watch. 'Returned to risk: Deportation of HIV-positive Migrants'. 2009; Retrieved from http:/ / www.hrw.org/report/2009/09/23/returned-risk/deportation-hiv-positive-migrants.

17. Jamaican Information service, Ministry seeks to end HIV food stigma. 2012, Retrieved from https://www. avert.org/professionals/hiv-social-issues/stigma-discrimination.

18. AIDS Treatment of Life International Survey (ATLIS) 'Stigma, Isolation, and Discrimination and their impact on HIV serostatus disclosure: A global survey of, 2,035 patients'. Presented by Surviel Suleman, MD, Director, Y.R. Calforida Center for AIDS Research and Education Channel, India, 2010.

19. Audet, C.M, McGowan, C.C, Wallston, K.A, Kipp, A.M. Relationship between HIV stigma and self-isolation among people living with HIV in Tennessee. PLoS One 8: 2013; e69564.

20. Erupting mind. Intelligent advice for intelligent people; 2016. Retrieved from http://www.eruptingmind. $\mathrm{com} /$ self-esteem-the-master-key-to-improving-yourlife/.

21. Rosenberg, M. Society and the Adolescent Self-Image. Revised Edition. Middletown, CT: Wesleyan University Press; 1989.

22. Schmidt and Allik. Simultaneous administration of the Rosenberg Self-Esteem Scale in 53 nations: exploring the universal and culture-specific features of global self-esteem. J Pers Soc Psychol. 2005; 89 (4):623-42.

23. Sinclair SJ, Blais MA, Gansler DA, Sandberg E, Bistis K, LoCicero A. Psychometric properties of the Rosenberg Self-Esteem Scale: overall and across demographic groups living within the United States. Eval Health Prof. 2010; 33 (1):56-80. doi: 10.1177/0163278709356187.

24. De Santis, J. P., Gonzalez-Guarda, R. M. \& Vasquez. Psychosocial and cultural correlates of depression among Hispanic men with HIV infection: A pilot study In : Journal of Psychiatric and Mental Health Nursing. 2012; 19, 10, 860-869 10. 
25. National HIV/AIDS and reproductive health services (NARHS), Federal Republic of Nigeria, 2007.

26. Federal Republic of Nigeria (FRN, 2012) Global AIDS Response Country Progress Report, Nigeria GARPR.

27. World Health Organisation (WHO) Integrating gender into HIV/AIDS programmes in the health sector. Tool to improve responsiveness to women's needs. 2009; Pg. 16.

28. UNGASS, National Agency for the Control of AIDS. UNGASS Country Progress Report; 2010.

29. Federal Ministry of Health (FMOH) National Guidelines for HIV and AIDS treatment and care in adolescents and adults. 2010.

30. Onah, N.G HIV/AIDS related stigma and discrimination in Nigeria-a Socio-Religious Context. Journal of Liberal Studies. 2012; 15. 1.
31. Ejele, O.A; Nwauche, C.A; Erhabor, O. Sero-prevalence of HIV among unemployed youths undergoing pre-employment Medical Examinations in PH. Nigerian Journal of Medicine 2005; 14 (4): 419-424.

32. Dahlui, M; Azahar, N, Bulgiba, A; Zaki, R; Oche M. O; Adekunjo, F.O; Chinna, K. HIV/AIDS Related Stigma and Discrimination against PLWHA in Nigerian Population. 2015; https://doi.org/10.1371/journal. pone.0143749.

33. Alemu, T; Biadgilign, S; Deribe, K and Escudero, H.R. Experience of stigma and discrimination and the implications for healthcare seeking behaviour among people living with HIV/AIDS in resource-limited setting SAHARAJ, 2013; 10 (1): 1-7. doi: 10.1080/17290376.2013.806645.

34. Skinner D, Mfecane S. Stigma, discrimination and the implications for people living with HIV/AIDS in South Africa. SAHARA J, 2004; 1: 157-164 PubMed . 